\title{
Are brief or recurrent transient global amnesias of epileptic origin?
}

\author{
Teresa P Melo, José M Ferro, Teresa Paiva
}

\begin{abstract}
To evaluate if short (less than one hour) or recurrent, or both, episodes of transient global amnesia (TGA) have an epileptic origin or carry a subsequent risk of epilepsy a group of patients with these types of TGA attacks was studied. The group was selected from a prospective series of 103 patients with TGA. Sixteen patients had an episode lasting less than one hour, 13 had more than one episode, and five patients had both short and recurrent attacks. For each patient the number of recurrences was small (four or less) and they were separated by months or years. During short attacks of TGA many subjects showed other typical features of TGA including repeated questioning (12 subjects) and performance of purposeful complex acts (eight subjects). Twelve short attacks were closely related to a characteristic precipitating event. During follow up only one patient had a seizure (partial motor). No other association between either short or repeated attacks of TGA and past history of epilepsy or paroxysmal discharges were seen on the EEG. Short or recurrent, or both, attacks of TGA are not epileptic and do not carry a relevant risk of subsequent seizures.
\end{abstract}

(F Neurol Neurosurg Psychiatry 1994;57:622-625)

Transient global amnesia (TGA) is a disorder whose pathogenesis is still unsettled. For most workers who have studied this disorder, epilepsy is an unlikely explanation for TGA. ${ }^{1-9}$ There are reports, however, of epileptic transient amnesia ${ }^{10-13}$ and pure amnestic seizures, ${ }^{14}$ and Hodges and Warlow ${ }^{1516}$ have identified a small subgroup $(7 \%)$ of subjects with short-lived or recurrent, or both, episodes of TGA who developed complex partial seizures on follow up. The objective of this study is to evaluate, in a prospective series of patients with TGA, if short or repeated, or both, episodes of TGA have an epileptic origin or carry a subsequent risk of epilepsy.

Subjects and methods

Since 1985 we have been asking other neurol- ogists to refer patients with TGA and we are conducting a prospective case-control, neuroimaging, neuropsychological, and follow-up study of this population. ${ }^{17}$

Transient global amnesia was defined as an episodic dysfunction of the central nervous system, during which there is a sudden loss of declarative memory for recent events without other neurological signs or symptoms, namely without any disturbance of vigilance, conciousness, language, cognition, praxis, or visuospatial functions. ${ }^{18-20}$ These attacks had to have been witnessed by a capable observer and there should have been no accompanying focal neurological symptoms or signs. Headache, nausea, and vomiting were allowable as associated symptoms during TGA. Patients who had had a head injury within the 72 hours preceding the amnestic period were not included.

Up to January 1993, 103 patients were enrolled in the study. Fifty-three were referred by other neurologists in the Lisbon area who were aware of our study. The remaining 50 patients were observed by one of the authors (TPM, JMF) at the emergency room (usually called by the neurologist on duty) or at the outpatient clinic. Nine other referred patients were excluded because they did not meet the inclusion criteria for TGA. All patients were interviewed and examined by us during the attack or a few days later, or both. In the first interview the patient and the witness were asked about the characteristics of the attack, precipitating factors or activity preceding the attack, cerebrovascular risk factors (hypertension, smoking, hypercholesterolaemia, hypertriglyceridaemia, heart disease, diabetes, high packed cell volume), and relevant previous medical history (previous TGA, migraine with or without aura, psychiatric illness, epilepsy, and recent head trauma). The following investigations were performed whenever possible: EEG, CT, carotid duplex scan, transcranial Doppler scan, and neuropsychological evaluation using the Weschler memory scale. Patients were then asked to come to our clinic annually or sooner if TGA recurred or any new neurological symptom developed. For those patients who did not attend the follow up, a telephone interview was performed.

For the purpose of this study only patients with (a) short (one hour or less) inception TGA, (b) multiple (more than one) attacks of TGA, or $(c)$ both short and multiple attacks and in revised for

Accepted 16 September 1993 
Patients with more than one episode of transient global amnesia (TGA) and at least one episode of TGA lasting less than one hour

\begin{tabular}{|c|c|c|c|c|c|}
\hline $\begin{array}{l}\text { Patient } \\
\text { no. }\end{array}$ & $\begin{array}{l}\text { Sex/age } \\
\text { (years) }\end{array}$ & Risk factors* & $\begin{array}{l}\text { Date of TGA episode } \\
\text { (duration (minutes)) }\end{array}$ & $\begin{array}{l}\text { EEG } \\
\text { results }\end{array}$ & $\begin{array}{l}\text { Seizures on } \\
\text { follow-up }\end{array}$ \\
\hline 25 & $M, 66$ & HTA & 1981 (120); $1984(30) ; 1985(30)$ & normal & \\
\hline 33 & $M, 69$ & HTA & $\begin{array}{l}\text { Sep } 1988(45) ; \text { Mar } 1989(30) \text {; } \\
\quad \text { Apr } 1990(60)\end{array}$ & \multirow{3}{*}{$\begin{array}{l}1989 \text { (normal); } \\
1990 \text { (left temporal } \\
\text { slow focus) } \\
\text { three normal; } 1989 \\
\text { (one during TGA) } \\
\text { normal }\end{array}$} & \multirow[t]{4}{*}{1989 (focal, motor) } \\
\hline 35 & F, 63 & \multirow{3}{*}{$\begin{array}{l}\text { HTA, } \\
\text { high cholesterol } \\
\text { HTA, migraine, } \\
\text { smoker, high } \\
\text { cholesterol } \\
\text { HTA, migraine }\end{array}$} & $\begin{array}{l}\text { Dec } 1988(60) \text {; Apr } 1989 \text { (480); } \\
\quad \text { Aug } 1989(720)\end{array}$ & & \\
\hline 42 & $F, 62$ & & $\begin{array}{l}1978(30) ; 1980(240) ; 1985(120) \\
1989(240)\end{array}$ & & \\
\hline 72 & F, 67 & & $\begin{array}{l}1989 \text { (60); Dec 1991 (240); } \\
\text { Mar 1992 (180) }\end{array}$ & two normal & \\
\hline
\end{tabular}

^HTA $=$ Hypertension.

(including the inception attack, previous and recurrent attacks) were selected and reported in detail.

\section{Results}

DURATION OF ATTACKS: SHORT TGAS

In sixteen $(16 \%)$ of 103 subjects with TGA investigated, the inception attack lasted one hour or less. Three short attacks lasted less than 30 minutes, five around 30 minutes, two between 30 and 60 minutes, and six lasted one hour. Three patients were examined by a neurologist during the attack and were judged to have typical TGA. Twelve subjects had repeated questioning and nine performed complex tasks such as driving, cooking, telephoning, and gardening during the episode. Twelve of these short episodes had typical precipitants (emotion, three; driving, one; sexual activity, one; effort, four; cough, one; heat exposure, one; angiography, one). No patient had a past history of seizures. Fourteen had an intercritical EEG performed. Two had focal (temporal) $\theta$ or $\theta-\delta$ slowing but none had paroxysmal EEG discharges. During follow-up (mean (SD) 27 (24) months, range 1-88) one patient, patient 33 (table), had three different recurrent episodes: a typical TGA, an episode of disorientation not detailed enough to be categorised, and a brief motor seizure of his right arm. A repeat EEG revealed a slow $(\theta)$ focus on the left nasopharyngeal lead and CT showed a right frontal calcification (probably cysticercosis).

NUMBER OF ATTACKS: RECURRENT TGAS Of the 103 subjects with TGA studied, 13 patients had more than one episode of TGA. Seven patients had an history of TGA before

Interval between contiguous attacks of transient global amnesia.

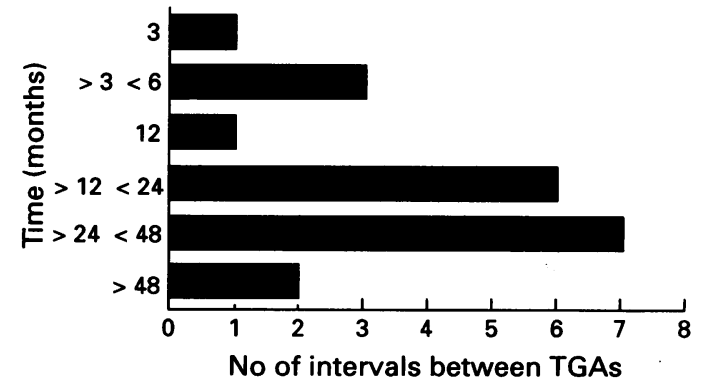

inclusion, four had recurrent episodes, and two had previous and recurrent episodes. Most (eight subjects) had only two episodes of TGA, four had three episodes, and one had four episodes of TGA. The median interval between two contiguous TGA episodes was 24 months (range 3-60) (figure).

Except for patient 33 who had a focal convulsion, no other patient had seizures on follow up.

\section{SHORT AND REPETITIVE TGAS}

The five patients with both short and repeated TGAs are summarised in the table. Recurrent TGAs were few (four or less) and separated by months or years. Despite EEGs being performed more than once in these patients, paroxysmal activity was never detected.

\section{Discussion}

The results of our series did not show any association between short (less than or equal to one hour) or recurrent episodes of TGA and epilepsy. There was no association with seizures in the past or paroxysmal discharges on the interictal EEG, and only one subject had a partial seizure on follow up, but not of the partial complex type. Half of our subjects with short attacks performed purposeful, intentional complex praxic acts, which indicates the preservation of procedural memory, in contrast with the disruption of episodic and semantic declarative memory. On the contrary, during partial complex epileptic seizures only relatively short and automatic sets of unlearned complex motor behaviour are displayed. Repeated questioning about the circumstances surrounding the attack is also a typical feature of TGA and was observed in three out of four of our subjects, whereas it is absent in pure amnestic seizures. ${ }^{14}$ Repeated questioning indicates awareness of the memory defect and preservation of metamemory. It is in fact an information seeking behaviour, trying to compensate for the memory storage disturbance. These two features seem more important for the differential diagnosis of TGA than simply the duration of the episode.

The idea that short, recurrent attacks of amnesia could have epileptic origin is not new or original. Deisenhamner ${ }^{12}$ presented a case 
of an 11-year-old girl who had four short attacks of amnesia over a five week period, two of them occurring in the same day. All except one (during which her pencil fell out of her hand) were typical of TGA. Prichard $e t$ $a l^{13}$ reported two sexagenarians who had recurrent circumscribed attacks of amnesia and bilateral temporal spikes on the EEG. One patient had 10 episodes lasting 10-15 minutes in four years that ceased with phenytoin treatment. The other patient had two episodes lasting one hour, six months apart. He was treated with carbamazepine, but he had a single short recurrence 22 months later, though associated with a subtherapeutic serum carbamazepine level. Miller et $a l^{5}$ obtained EEGs in 109 patients with TGA alone, in five patients who had TGA and epilepsy, and in three patients with epileptic amnesia alone. They concluded that genuine epileptiform activity was observed only among patients who had seizure disorders. None of the ictal recordings showed seizure discharges. Only one patient had interictal epileptic activity on his awake EEG: he had several episodes of amnesia in one day and developed complex partial seizures within a few weeks. Three subjects had potentially epileptogenic activity during sleep recordings. Patient 1 had three spells in three months, and nine months later five similar spells all lasting less than 30 minutes; phenytoin stopped the episodes. Patient 2 had four typical TGAs (separated by years or months) lasting hours and probably unrelated sensory seizures. Patient 3 had a single long TGA episode followed years later by partial complex seizures. Miller et al state that amnesic spells due to seizures are more apt to be brief and recurrent. They also report that epileptic amnesia can be longer if a cluster of seizures occur. Further description of epileptic amnestic attacks are those of Gallassi et $a l^{10}$ and Stracciari et al. ${ }^{11}$ The three patients of Gallassi et al had short episodes of ictal memory loss with brief loss of contact and oral automatisms. The frequency of attacks was relatively high, ranging from daily spells to one every few months. Stracciari et al report a patient who had eight to 15 attacks in eight months lasting a few minutes and had another episode lasting seven hours that started with automatisms. Hodges and coworkers, 151621 in a retrospective-prospective study of 114 patients with TGAs found that subjects with brief and recurrent episodes of TGA were at risk for further seizures. In their series $7 \%$ of patients with TGA developed epilepsy. Methodological issues or differences in inclusion criteria may explain the discrepancy between their series and ours. Firstly, mode of referral: in our study, TGA was diagnosed either by one of the authors or referred by other neurologists; in Hodges and Warlow's study most of the patients were referred by general practitioners. Secondly, our data were obtained prospectively, whereas about half of Hodges and Warlow's patients were collected retrospectively. Although Hodges and Warlow interviewed patients and witnesses again, the time gap between the episode and the interview makes their testimony less reliable and the differential diagnosis between TGA, epileptic transient amnesia, pure amnestic seizures, or a prolonged post-ictal amnesia difficult to make.

Palmini et $a l^{14}$ studied eight patients with pure amnestic seizures. These type of attacks are defined as seizures during which the only clinical manifestation is an inability to retain in memory what occurs during the seizure, coupled with the preservation of other cognitive functions and the ability to interact normally with their physical and social environment. These patients also had unmistakable conventional complex partial seizures. In seven patients attacks were preceded by a typical aura. During the attacks patients (and observers) were not aware that there was anything wrong with them, becoming aware of that only after the event. Patients with pure amnestic seizures had no retrograde amnesia for events before the seizure. All these patients had interictal EEG evidence of mesial temporal dysfunction.

Epileptic transient amnesia, either ictal or postictal, ${ }^{22} 23$ should not be confused with transient global amnesia. Epileptic amnesic episodes are not only briefer (usually lasting minutes) but also more numerous (more than four; even more than one a day) and recur at short intervals. Automatisms and staring are seen during some of these episodes and they are often preceded by a typical aura. Patients usually also have other types of partial complex seizures. Transient global amnesia rarely recurs and, as our series shows, recurrent TGAs are few and separated by months or years. Typical precipitant events and repeated questions can be found in about $75 \%$ of the short TGA attacks and are absent in epileptic transient amnesia. Anticonvulsant drugs and driving limitations should only be recommended for epileptic transient amnesia. Although the relative prevalence of TGA and pure amnestic seizures is not known, this type of seizure is probably rare. It is rarely seen in epileptic clinics ${ }^{13}$ and we could not find any such case among all the amnestic spells referred to us.

1 Heathfield KWG, Croft PB, Swash M. The syndrome of transient global amnesia. Brain 1973;96:729-36.

2 Cole AJ, Gloor P. Transient global amnesia: the electroencephalogram at onset. Ann Neurol 1987;22:771-2.

3 Shuping JR, Rollinson RD, Toole JF. Transient globa amnesia. Ann Neurol 1980;7:281-5.

4 Kushner MJ, Hauser WA. Transient global amnesia: a case control study. Ann Neurol 1985;18:684-91.

5 Miller JW, Yanagihara T, Petersen RC, Klass DW. Transient global amnesia and epilepsy: electroencephalographic distinction. Arch Neurol 1987;44: 629-33.

6 Jacome DE. EEG features in transient global amnesia. Clin Electroencephalogr 1989;20:183-92.

7 Guidotti M, Anzalone N, Morabito A, Landi G. A casecontrol study of transient global amnesia. F Neurol Neurosurg Psychiatry 1989;52:320-3.

8 Rowan AJ, Protass L. Transient global amnesia: clinical and electroencephalographic findings in 10 cases. and electroencephalographic

9 Gallassi R, Morreale A. Transient global amnesia and epilepsy. In: Markowitsch JH, ed. Transient global amnesia and related disorders. Toronto: Hogrefe and Huber, 1990:58-65.

10 Gallassi R, Morreale A, Lorusso S, Pazzaglia P, Lugaresi 
E. Epilepsy presenting as memory disturbances. Epilepsia 1988;29:624-9.

11 Stracciari A, Ciucci G, Bianchedi G, Rebucci GG Epileptic transient amnesia. Eur Neurol 1990;30:176-9. 12 Deisenhammer E. Transient global amnesia as an epileptic manifestation. $\mathcal{F}$ Neurol 1981;225:289-92.

13 Pritchard PB, Holmstrom VL, Roitzsch JC, Giacinto J. Epileptic amnesia attacks: benefit from antiepileptic drugs. Neurology 1985;35:1188-9.

14 Palmini AL, Gloor P, Jones-Gotman M. Pure amnestic seizures in temporal lobe epilepsy. Brain 1992;115: 749-69.

15 Hodges JR, Warlow CP. The aetiology of transient global amnesia. A case control study of 114 cases with amnesia. A case control study of 114 cases

16 Hodges JR, Warlow CP. Syndromes of transient amnesia: towards a classification. A study of 153 cases. $₹$ Neurol Neurosurg Psychiatry 1990;53:834-43.
17 Melo TP, Ferro JM, Ferro H. Transient global amnesia. A case control study. Brain 1992;115:261-70.

18 Bender MB. Syndrome of isolated episode of confusion with amnesia. Fournal of the Hillside Hospital 1956;5: 212-5

19 Fisher CM, Adams RD. Transient global amnesia. Acta Neurol Scand Suppl 1964;40(suppl 9):1-83.

20 Caplan LB. Transient global amnesia. In: Vinken PJ, Bruyn GW, Klawans HL, eds. Handbook of clinical neurology. Vol. 45. Amsterdam: Elsevier, 1985:205-18.

21 Hodges JR. The Oxford TGA study. In: Hodges JR, ed. Transient amnesia clinical and neuropsychological aspects. Transient amnesia clinical and neuropsyct

22 Morrell F. Memory loss as a Todd's paralysis. Epilepsia 1980;21:185.

23 Tassinari CA, Ciarmatori C, Alesi C, et al. Transient global amnesia as a postical state from recurrent partial seizures. Epilepsia 1991;32:882-5.

\section{Nicolaus Petreus Tulpius (1593-1674) on headaches}

Nicolaus Pietersz Dirksz, son of Pieter Dirksz, a merchant, was born in Amsterdam, The Netherlands, on 11 October 1593. He studied under Pauw and Bontius at Leiden. He changed his name, adopting the tulips which adorned the façade of his home on Keizersgracht. A fine anatomist, pathologist, and physician, he provided early descriptions of the ileocaecal valve (Tulp's valve), angina interna, kidney stones, a bronchial cast, beriberi indorum, and tapeworms. Tulp is immortalised by his friend Rembrandt in The anatomy lesson, to be seen in the Rijksmuseum, Amsterdam, which shows Tulp, in an exquisite lace collar and tassels, dissecting before a group of surgeons.

In his "golden work" (Haller) Observationes medicae, published in 1641 (fig), Tulp described a fat man who had suffered from severe headaches for a considerable time. ${ }^{1}$ Several treatments had failed. "He asked nature for help, ... and lost a great amount of fluid from the nose ... (and) was relieved in a short period of time."

Being a Hippocratic physician, Tulp cited the aphorism (Aph. 10, Book VI): "who has headache, and is very sick, and if matter, water and blood escapes from the nose or ears, will be cured". We are left to wonder whether this was a transient CSF leak from head injury or hydrocephalus.

Tulp also relates the story of "the carpenter's wife who had headaches for many years, accompanied by a warm feeling ascending from the foot to the head and back to the big toe. Tulp ordered cupping by which the volatile spirit could drain from the body; the patient recovered soon."

$\mathrm{He}$ distinguishes between cephalia-headache accompanying febrile illnesses, and cephalalgiarecurring endogenous headache.

He tells of an Isaak van Halmaal who:

.... in the beginning of the summer season, was inflicted with a very severe headache, occurring and disappearing daily on fixed hours, with such intensity, that he often assured me that he could not bear the pain any more or he would succumb shortly. For rarely it lasted longer than two hours. And the rest of the day there was no fever, nor indisposition of the urine, nor any infirmity of the pulse. But this recurring pain lasted until the fourteenth day ...".2

The usual treatment with cupping or blister-raising plasters applied to the occiput gave no relief. The description suggests cluster headache although unilateral pain, lacrimation, and redness of the eye were not mentioned.

I have mentioned elsewhere the later account of probable cluster headache by Thomas Willis in $D e$ anima brutorum published in 1672, who described a venerable matron who began to suffer every afternoon at $4 \mathrm{pm}$ from recurring severe headache. ${ }^{3}$ In 1747
Joannes Christoph Ulricus Oppermann published his little acknowledged dissertatio medica inauguralis, entitled Hemicrania horologica which may be the first account of the variant, chronic paroxysmal hemicrania. The later depiction of cluster headache awaited the doubtful account of Benjamin Hutchinson and the more convincing description of Romberg in his $A$ manual of nervous diseases in man, 1853. JMS PEARCE
304 Beverley Road,

Anlaby, Hull HU10 7BG, UK

1 Tulp NP. Observationes medicae, 5th edn. Book 1, Ch 13, Leiden: Vivie, 1716.

2 Koehler PJ. Headache in Tulp's Observationes medicae (1641) with description of cluster-headache. Paper read to 3rd meeting Anglo-Dutch Migraine Association, The Hague, The Netherlands, 7 May 1993.

3 Pearce JMS. Early descriptions of cluster headache. $f$ Neurol Neurosurg Psychiatry 1989;52:466.

I am greatly indebted to Dr P J Koehler of Heerlen, The Netherlands for his translation and permission to quote from his paper.

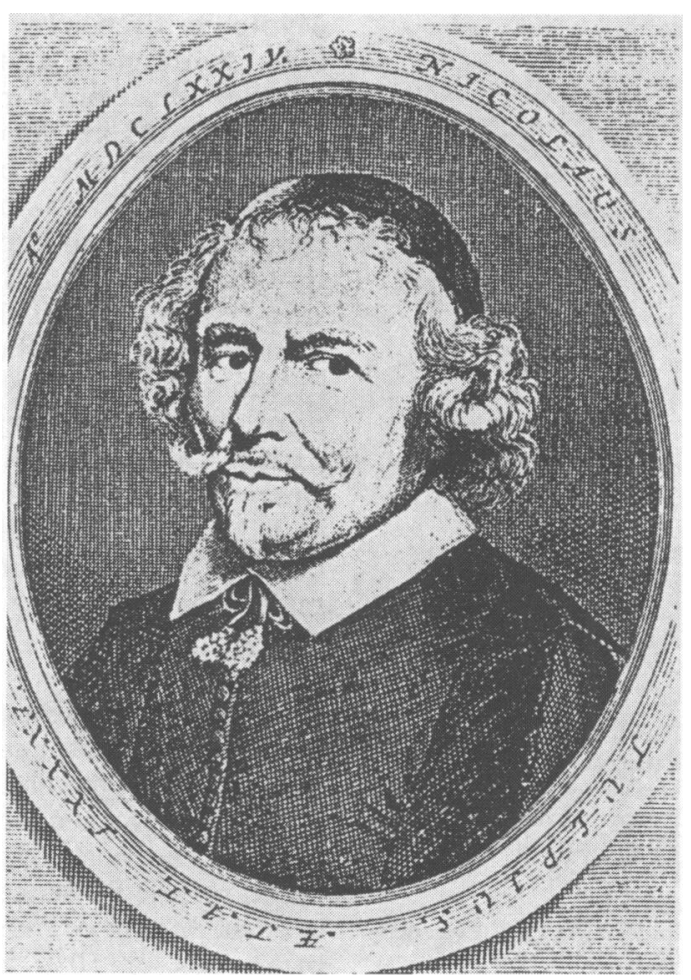

Nicholas Tulp (1593-1674). Engraving by L. Visscher (frontispiece to Observationes medicae). ${ }^{1}$

See also p. 637 